\title{
APPLYING GREY SYSTEM THEORY TO FORECAST THE TOTAL VALUE OF IMPORTSAND EXPORTS OF TOP TRADED COMMODITIES IN TAIWAN
}

\section{THANH-TUYEN TRAN*}

\author{
Research Center of Applied Sciences, Lac Hong University, No. 10 Huynh Van Nghe, Bien Hoa City, \\ Dong Nai Province, Vietnam
}

*Corresponding author: copcoi2@gmail.com

\begin{abstract}
Export contributes to a large extent to economic growth of an island-type economylikeTaiwan. The scientific forecasting on the total value of imports and exports of top traded commodities in Taiwan are needed as the essential inputs to determine whether new top traded commodities should be imported or exported, and to make right decision toward activities in various functional areas such as building new container terminals, operation plans, marketing strategies, as well as finance and accounting [1]. Taking the original data of the amount of import and export commodity during the years from 2007 to 2013, the author tries to establish a mathematical model of Grey forecasting to make a prediction of the total value of imports and exports of top commodities in Taiwan for the next 05 coming years from 2014 to 2018. The analysis results show that the usage of Grey forecasting models resulted in a very low mean absolute percentage error, which demonstrate its applicability in practice to provide accurate forecasts. This research also indicates that for the future period of time (2014-2017), there will be a steady increase in both exports and imports value of all top commodities. The current study may offer a good idea for the control and scheduling for the terminal operators in decision making and planning.
\end{abstract}

Received 2018-11-12; accepted 2019-01-09; published 2019-03-01.

2010 Mathematics Subject Classification. 91B02.

Key words and phrases. Grey system theory, Taiwan, trade policy, top commodities, forecasting.

(C)2019 Authors retain the copyrights

of their papers, and all open access articles are distributed under the terms of the Creative Commons Attribution License. 


\section{INTRODUCTION}

International trade refers to the exchange of capital, commodities, and services across international borders or territories [2]. Import and export trade is a major component of international trade [3] and the positive contribution of import and export trade is one of the primary factors keeping the national economy growth.Imports can be a channel for long-run economic growth because it provides domestic firms with access to needed intermediate factors and foreign technology ([4]; [5]; [6]).Growth in imports can serve as a medium for the transfer of growth-enhancing foreign research and development knowledge from developed to developing countries [7].

Export expansion and openness to foreign markets is viewed as a key determinant of economic growth because of the positive externalities it provides. For example, firms in a thriving export sector can enjoy the following benefits: efficient resource allocation, greater capacity utilization, exploitation of economies of scale, and increased technological innovation stimulated by foreign market competition [8]. Furthermore, exports can provide foreign exchange that allows for more imports of intermediate goods which in turn raises capital formation and thus stimulate output growth and lead to an expansion of production and employment ([9]; [10]).

It has been proven that, there is relationship between import and export trade for the growth of cross-country economies and as stated in the works of Liu [11], Azgun and Sevinc [12], Alam et al. [13], Zhang and Zhao [14], and Wong [15]. The causal relationship between trade and economic growth for Bulgaria, Czech Republic, and Poland was examined in the paper of Awokuse [8] and this analystconfirmed that trade stimulates economic growth. These developing countries depend on exports for economic growth, which gives rise to the 'exportled growth' hypothesis. The export-led growth hypothesis entails pursuing policies to promote exports and acquire foreign currency reserves, and countries achieve economic growth by importing high-technology goods.Causality between exports, imports, and economic growth is not limited to developing countries like Bulgaria [16], and previous studies have been examined this reality at developed countries, for example Taiwan by Chuang [17], Portugal by Ramos [18], China by Mah [19], and Korea by Awokuse [4]. Some studies have been conducted of newly industrialized Asian countries by Thangavelu and Rajaguru [20]; of India by Joseph and Harilal [21], of Malaysia by Milad et al. [22]. 
The import and export trade normally requires organizational cooperation among different international sectors ranging from purchasing, manufacturing, transporting, inventory, distribution, etc., especially the engagement of the customs authorities in both the country of export and the country of import ([23]; [24]). For this reason, it is necessary to build suitable plans and strategy to guarantee the flow of international trade across nations become smoothly. In order to have proper plans, accurately forecast the volume of imported-exported goods is the core issue.

Grey forecasting models have recently popularly used in time-series forecasting due to their simplicity and ability to characterize an unknown system with few data points ([25]; [26]). Grey system has been widely employed in different areas due to its ability to deal with the problems of uncertainty with few data points and/or "partial known, partial unknown" information. For having accurately forecasting results of the value of imported and exported goods, the author considers that it is very suitable to apply Grey system theory with its GM $(1,1)$ in this study.

Grey system theory is a useful research tool for scientific world, which was formulated by Professor Deng Julong in 1982 to study the problems of less data, poor information and uncertainty ([27]; [28]; [29]). In order to make positive analysis about the changes inthe total value of imports and exports of top traded commodities in Taiwan educational system from 2007 to 2013, and to make a prediction of these problemsfor the next 05 coming years from 2014 and 2018, Grey system theory with its GM $(1,1)$ is applied. There will be some suggestions provided in the last chapters to the government and related organizations to deal with the changing in forecasted numbers. Furthermore, future works would continue to apply this method, and then if it's still successful, there would be very good for any nation. One of the main reasons for this objective is that there is a few prediction methods applied to forecast the top traded commodities value of import/export, so this would contribute a lot of things to the whole country education development in long-term.

\section{METHODOLOGY}

\subsection{Calculation and Applying GM(1,1) Based on MATLAB}

The researchers use GM $(1,1)$ model to predict the realistic factors for the next 4 years (2014 to 2017). The study takes the exports of FOOD and LIVE ANIMALS in the data set of Taiwan as example to understand how to compute in GM (1,1) model in period 2007-2013, and other variables are calculated in the same way. The procedure is carried out step by step as following. 
First, the researchers use the GM $(1,1)$ model for trying to forecast the variance of primitive series

Creating the primitive series:

$\mathrm{X}^{(0)}=(1836 ; 2259 ; 1914 ; 2401 ; 2942 ; 3286 ; 3215)$

Step 1. Grey generation (by the method of AGO)

First AGO series:

$$
x^{(1)}=\left(x^{(1)}(1), x^{(1)}(2), x^{(1)}(3), x^{(1)}(4), x^{(1)}(5), x^{(1)}(6), x^{(1)}(7)\right)
$$

$\mathrm{X}^{(1)}=(1836 ; 4095 ; 6009 ; 8410 ; 11352 ; 14638 ; 17853)$

$$
\begin{gathered}
\mathrm{X}^{(1)=} \mathbf{X}^{(0)}(1)=1836 \\
x^{(1)}(2)=x^{(0)}(1)+x^{(0)}(2)=4095 \\
x^{(1)}(3)=x^{(0)}(1)+x^{(0)}(2)+x^{(0)}(3)=6009 \\
x^{(1)}(4)=x^{(0)}(1)+x^{(0)}(2)+x^{(0)}(3)+x^{(0)}(4)=8410 \\
x^{(1)}(5)=x^{(0)}(1)+x^{(0)}(2)+x^{(0)}(3)+x^{(0)}(4)+x^{(0)}(5)=11352 \\
\boldsymbol{x}^{(\mathbf{1})}(\mathbf{6})=x^{(0)}(1)+x^{(0)}(2)+x^{(0)}(3)+x^{(0)}(4)+x^{(0)}(5)+x^{(0)}(6)=14638 \\
\boldsymbol{x}^{(\mathbf{1})}(\mathbf{7})=x^{(0)}(1)+x^{(0)}(2)+x^{(0)}(3)+x^{(0)}(4)+x^{(0)}(5)+x^{(0)}(6)+x^{(0)}(7)=17853
\end{gathered}
$$

Step 2. Create the different equations of GM $(1,1)$

To find $X^{(1)}$ series, and the following mean obtained by the mean equation is:

$\mathrm{z}^{(1)}(2)=\frac{1}{2}(1836+4095)=2965.5$

$\mathrm{z}^{(1)}(3)=\frac{1}{2}(4095+6009)=5052$

$\mathrm{z}^{(1)}(4)=\frac{1}{2}(6009+8410)=7209.5$

$\mathrm{z}^{(1)}(5)=\frac{1}{2}(8410+11352)=9881$

$\mathrm{z}^{(1)}(6)=\frac{1}{2}(11352+14638)=12995$

$\mathrm{z}^{(1)}(7)=\frac{1}{2}(14638+17853)=16245.5$

Step 3. Solve equations:

To find $a$ and $b$, the primitive series values are substituted into the Grey differential equation to obtain: 


$$
\left\{\begin{array}{c}
2259+a \times 2965.5=b \\
1914+a \times 5052=b \\
2401+a \times 7209.5=b \\
2942+a \times 9881=b \\
3286+a \times 12995=b \\
3215+a \times 16245.5=b
\end{array}\right.
$$

Convert the linear equations into the form of a matrix:

Let $B=\left[\begin{array}{c}-2965.5 \\ -5052 \\ -7209.5 \\ -9881 \\ -12995 \\ -16245.5\end{array}\right], \hat{\theta}=\left[\begin{array}{l}a \\ b\end{array}\right], y_{N}=\left[\begin{array}{c}2259 \\ 1914 \\ 2401 \\ 2942 \\ 3286 \\ 3215\end{array}\right]$

And then use the least square method to find $a$ and $b$

$$
\left[\begin{array}{l}
a \\
b
\end{array}\right]=\hat{\theta}=\left(B^{T} B\right)^{-1} B^{T} y_{N}=\left[\begin{array}{c}
-0.101237218 \\
1752.484844
\end{array}\right]
$$

Use the two coefficients $a$ and $b$ to generate the whitening equation of the differential equation:

$$
\frac{d x^{(1)}}{d t}(-0.101237218) \times x^{(1)}=1752.484844
$$

Find the prediction model from Equation:

$$
\begin{aligned}
& X^{(1)}(k+1)=\left(X^{(0)}(1)-\frac{b}{a}\right) e^{-a k}+\frac{b}{a} \\
& x^{(1)}(k+1)=\left(1836-\frac{1752.484844}{-0.101237218}\right) e^{0.10123728 \mathrm{k}}+\frac{1752.484844}{-0.101237218}
\end{aligned}
$$

Substitute different values of $\mathrm{k}$ into the equation:

$$
\begin{array}{ll}
\mathrm{k}=0 & X^{(1)}(1)=1836 \\
\mathrm{k}=1 & X^{(1)}(2)=3875.869833 \\
\mathrm{k}=2 & X^{(1)}(3)=6133.065564 \\
\mathrm{k}=3 & X^{(1)}(4)=8630.74090 \\
\mathrm{k}=4 & X^{(1)}(5)=11394.5163 \\
\mathrm{k}=5 & X^{(1)}(6)=14452.741 \\
\mathrm{k}=6 & X^{(1)}(7)=17836.7880 \\
\mathrm{k}=7 & X^{(1)}(8)=21581.3674 \\
\mathrm{k}=8 & X^{(1)}(9)=25724.89103
\end{array}
$$




$$
\begin{array}{ll}
\mathrm{k}=9 & X^{(1)}(10)=30309.8618 \\
\mathrm{k}=10 & X^{(1)}(11)=35383.3113
\end{array}
$$

Derive the predicted value of the original series according to the accumulated generating operation and obtain:

\begin{tabular}{ccccrc}
\hline Year & $\begin{array}{l}\text { k } \\
\text { value }\end{array}$ & Actual value & $\begin{array}{c}\text { Forecasted } \\
\text { value }\end{array}$ & $\begin{array}{c}\text { Residual } \\
\text { error }\end{array}$ & Error \\
\hline 2007 & $\mathbf{0}$ & 1,836 & 1836 & 0 & $0.0000 \%$ \\
2008 & 1 & 2,259 & 2040 & $(219)$ & $-9.7003 \%$ \\
2009 & 2 & 1,914 & 2257 & 343 & $17.9308 \%$ \\
2010 & 3 & 2,401 & 2498 & 97 & $4.0265 \%$ \\
2011 & 4 & 2,942 & 2764 & $(178)$ & $-6.0579 \%$ \\
2012 & 6 & 3,286 & 3058 & $(228)$ & $-6.9317 \%$ \\
2013 & 7 & 3,215 & 3384 & 169 & $5.2580 \%$ \\
2014 & 8 & -- & 3745 & -- & $?$ \\
2015 & 9 & -- & 4144 & -- & $?$ \\
2016 & 10 & -- & 4585 & -- & $?$ \\
2017 & 11 & -- & 5073 & -- & $?$ \\
\hline
\end{tabular}

After next, this paper uses the Matlab with the forecasting method on Grey system model.

\subsection{MATLAB Introduction}

Matlab is built on the matrix for the data unit - even basic, and it has the ability to do straightly calculations or operations as product of matrix, involution of matrix, division of matrix and sparse matrix, etc. In the language system of Matlab, nearly all operations are run on matrix operation, and it also can apply the method analogous to mathematical formula to compile a program and realize algorithm, which can ease the problems with less time on doing operations. Nevertheless, the process of grey forecasting requires a large amount of matrix operations and progression to be done well, which Matlab can handle them usefully and conveniently. It is believed to make the right decision to combine Matlab with $\operatorname{GM}(1, N)$ to realize algorithm of grey forecasting.

\subsubsection{Program of Grey System Forecasting Based on MATLAB}

The basic mathematical model of Grey system $\mathrm{GM}(1,1)$ is the foundation to make progress for the program of grey forecasting based Matlab. This program can handle such kinds of data like data of a single point, set up a forecasting model automatically, dynamically output and display curvilinear figure of the model, forecast all parameters and model equation error terms, and 
predict future value of one time series or some time series based on the predicted time series set.Following is the Flow chart of GM(1,1) based on MATLAB (Figure 2.1).

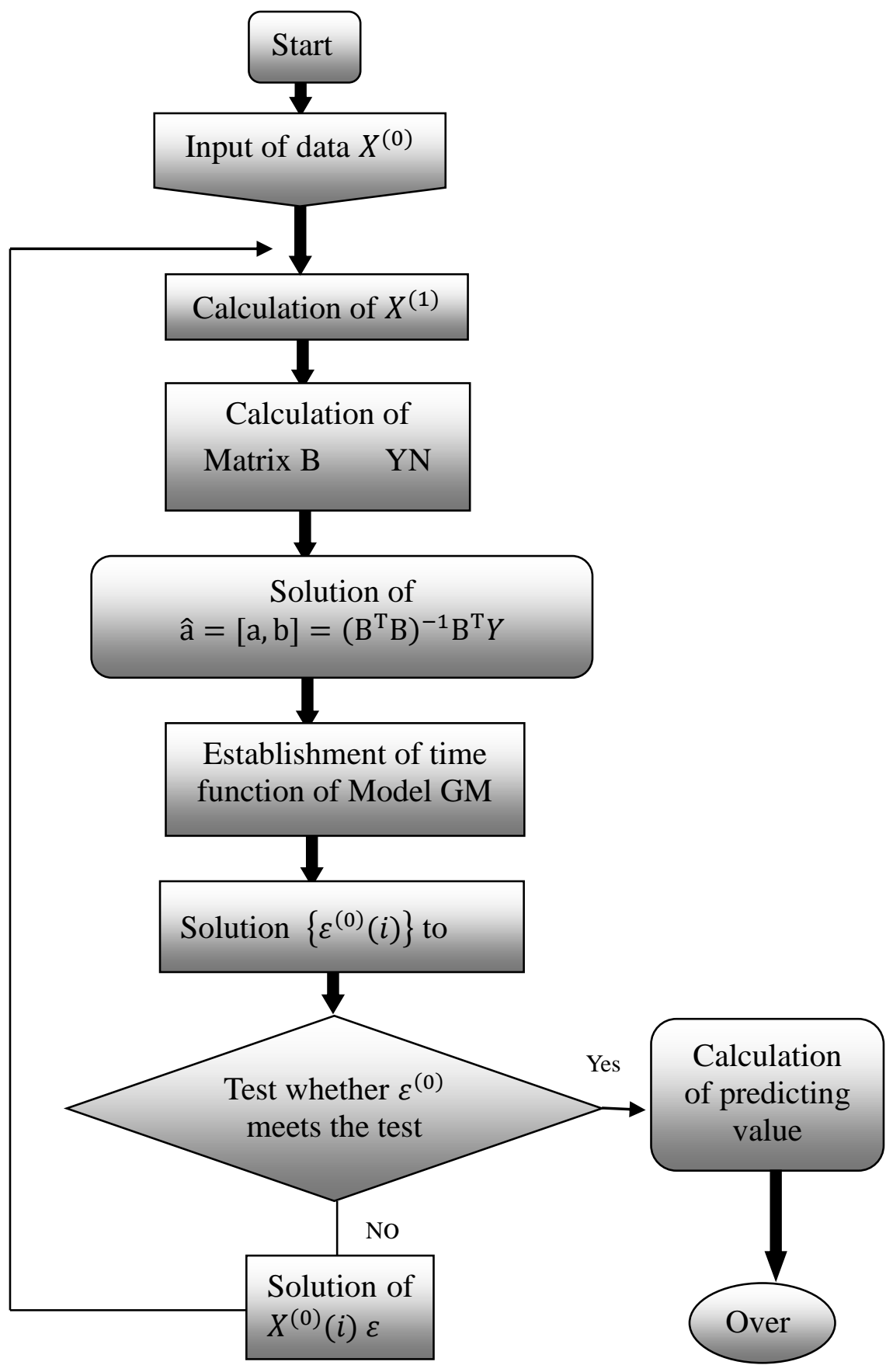

Figure 2.1: The Flow Chart of GM $(1,1)$ based on MATLAB 


\subsubsection{Accuracy Test and Optimization of the Model}

Sample of Forecasting of Model GM $(1,1)$

This paper conducts a practical forecasting on the exports of FOOD and LIVE ANIMALS in the data set of Taiwan by adopting the above Model GM(1,1), and checks the predicted results by means of relative error test.

Accuracy inspection analysis of forecasting ability

Numerous methods exist for judging forecasting model accuracy, and no single recognized inspection method exists for forecasting ability. Mean Absolute Percentage Error (MAPE) is often used to measure forecasting accuracy.

(MAPE) is measure of accuracy in a fitted time series value in statistics, specifically trending. It usually expresses accuracy as a percentage

(1)wikipedia.orghttp://en.wikipedia.org/wiki/Mean_absolute_percentage_error

Smaller MAPE value indicates better forecasting ability.

MAPE $=\frac{1}{n} \sum \frac{\mid \text { Actual }- \text { Forecast } \mid}{\text { Actual }} \times 100$

$n$ Forecasting number of step

Evaluation of MAPE forecasting ability is divided forecasting ability is evaluated as follows:

- $\quad<10$ Excellent forecasting ability

- 10 20 Good forecasting ability

- 20 50 Reasonable forecasting ability

- $\quad>50$ Poor forecasting

In order to ensure that the GM $(1,1)$ based on MATLAB has high accuracy for application in predicting the number in reality, this paper takes out the exports of FOOD and LIVE ANIMALS in the data set of Taiwan estimated by GM $(1,1)$ based on Matlab as 3384 which is very close to the original number 3,215 and the error is so small in table 2.1. Moreover, repeating above processes in the Table 2.1 showing the sample calculation by $\operatorname{GM}(1,1)$ based on MATLAB, it points out that the forecasting error ranging from only $4.0265 \%$ to $17.9308 \%$ in the sample predicted academic years. The result reveals that grey prediction is a good method for prediction. 
Table 2.1: The original and prediction values and errors and AGO (2007 2014)

\begin{tabular}{rllrrr}
\hline Year & Actual value & $\begin{array}{c}\text { Forecasted } \\
\text { value }\end{array}$ & $\begin{array}{c}\text { Residual } \\
\text { error }\end{array}$ & $\begin{array}{c}\text { Error } \\
\%\end{array}$ & AGO \\
\hline $2007-08$ & 1,836 & 1836 & 0 & $0.0000 \%$ & 1,836 \\
$2008-09$ & 2,259 & 2040 & $(219)$ & $9.7003 \%$ & 4,095 \\
$2009-10$ & 1,914 & 2257 & 343 & $17.9308 \%$ & 6,009 \\
$2010-11$ & 2,401 & 2498 & 97 & $4.0265 \%$ & 8,410 \\
$2011-12$ & 2,942 & 2764 & $(178)$ & $6.0579 \%$ & 11,352 \\
$2012-13$ & 3,286 & 3058 & $(228)$ & $6.9317 \%$ & 14,638 \\
$2013-14$ & 3,215 & 3384 & 169 & $5.2580 \%$ & 17,853 \\
\hline
\end{tabular}

\section{RESULTS AND ANALYSES}

\subsection{Calculations on the Exports and Imports}

In this section, the calculations on the total the value exports of top commodities in Taiwan during the recent and future years are mentioned; moreover, prediction values for the 4 years 2014 to 2017 are typically focused.

\section{Food and live animals}

The following grey prediction GM $(1,1)$ model estimates the export value of food and live animal. The total value is rising from \$US3745 million in 2014 to \$US 5073 million in 2017 respectively. The forecasting errors are ranging from only $0.00 \%$ to $17.93 \%$, which indicates good predicting ability of GM(1,1).Figure 3.1 clearly indicates the steadily growth of the value of exporting thiscommodity in Taiwan. Through the 10-year time (2007 to 2017), the value of export has been slightly increasingbyseveral hundreds of \$US million per year as forecasted. 
Table 3.1: Food and live animals as predicted

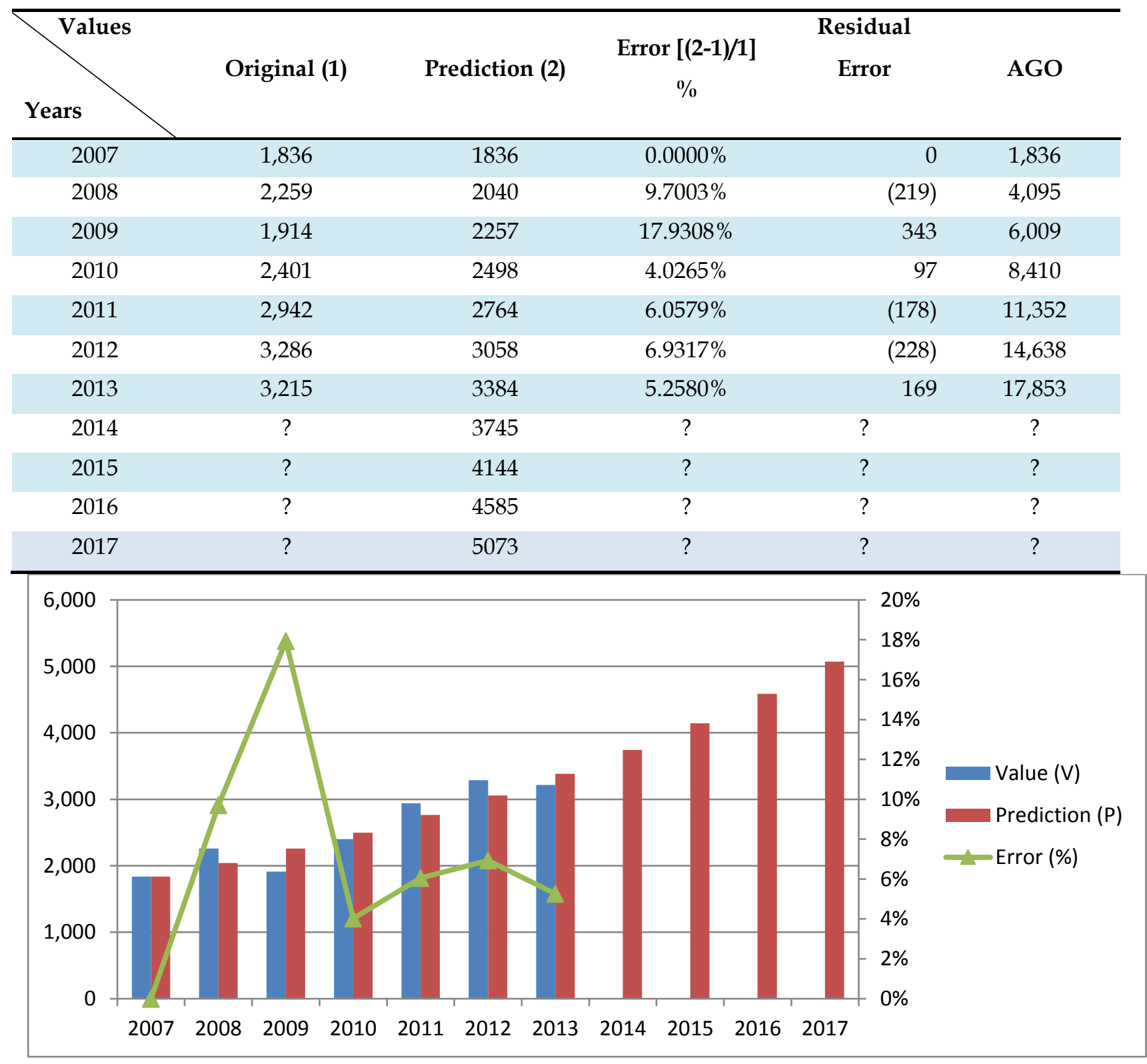

Figure 3.1: The sequence step of Food and live animals as predicted

\section{Beverages and tobacco}

The next below is the prediction for the export value of beverages and tobacco. Table 3.2 and figure 3.2 indicate a steady increase in the export value of these commodities in the next following four year. The prediction results for next 4 years from 2014 to 2017 show Taiwan export for beverages and tobacco amounted to around: \$US 564 million; \$US 11622 million; \$US 
11940 million and \$US 12267 million. We also notice the prediction errors which are ranged from only $0.0000 \%$ to $18.4191 \%$, interpreted good results.

Table 3.2: The numbers of Beverages and tobacco as predicted

\begin{tabular}{rccccrc}
\hline Values & & & Error [(2-1)/1] & $\begin{array}{c}\text { Residual } \\
\text { Error }\end{array}$ & AGO \\
\hline 2007 & & Priginal (1) & & & \\
\hline 2008 & 101 & 101 & $0.0000 \%$ & 0 & 101 \\
2009 & 143 & 169 & $18.4191 \%$ & 26 & 244 \\
2010 & 197 & 207 & $5.0347 \%$ & 10 & 441 \\
2011 & 270 & 253 & $6.3567 \%$ & $(17)$ & 711 \\
2012 & 338 & 309 & $8.5960 \%$ & & $(29)$ & 1,049 \\
2013 & 370 & 378 & $2.0285 \%$ & & 8 & 1,419 \\
2014 & 450 & 461 & $2.5066 \%$ & & 11 & 1,869 \\
2015 & $?$ & 564 & $?$ & $?$ & $?$ \\
2016 & $?$ & 689 & $?$ & $?$ & $?$ \\
2017 & $?$ & 842 & $?$ & $?$ & $?$ \\
\hline
\end{tabular}

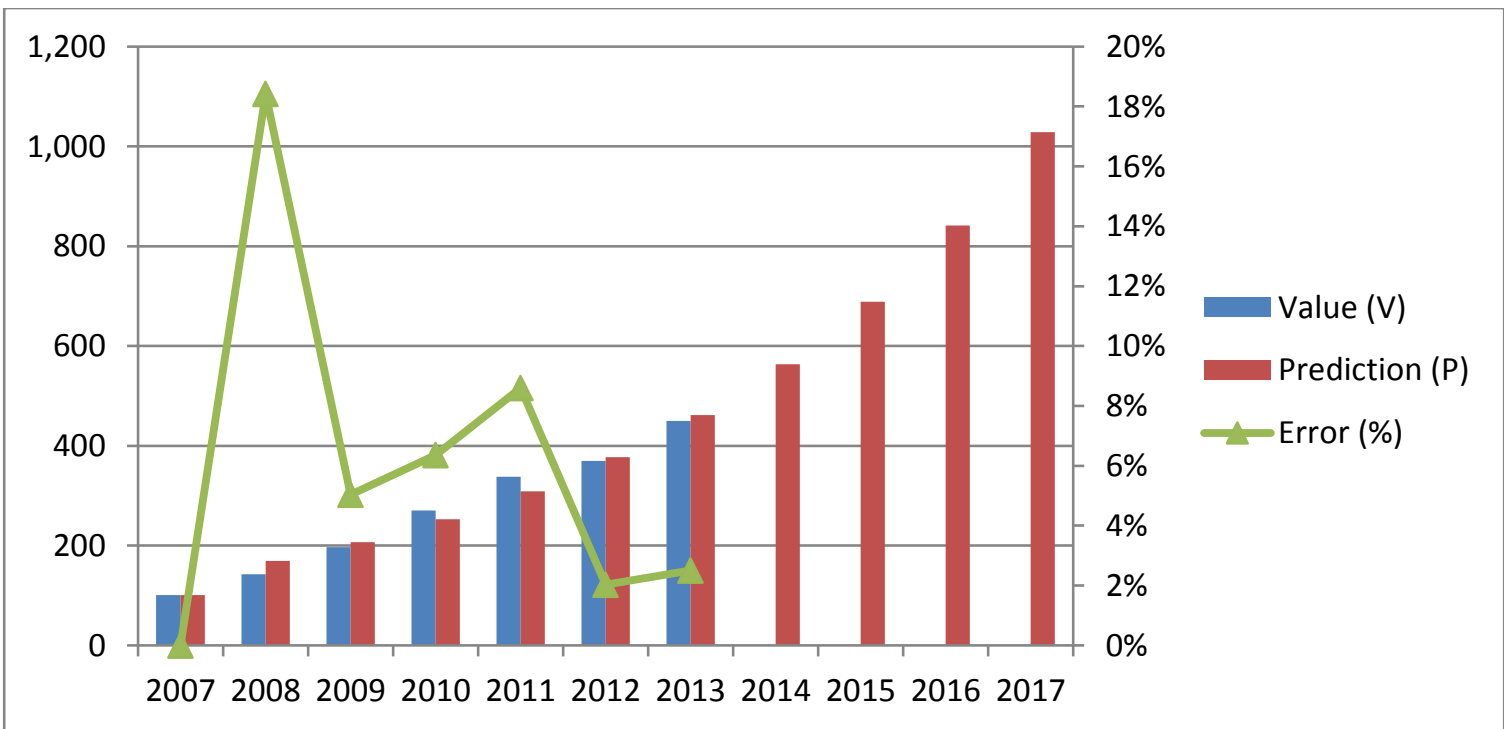

Figure 3.2: The sequence step of Beverages and tobacco as predicted 


\section{Crude materials, inedible, except fuels}

The next below is the prediction for the export value of crude materials, inedible, and except fuel. Table 3.3 and figure 3.3 indicate a steady increase in the export value of this kind of goods in the next year. The total value of exporting this merchandise is rising from $\$$ US 4226 million in 2014 to \$US 4780 million in 2017 respectively. We also notice the prediction errors which are ranged from only $0.0000 \%$ to $27.496 \%$, interpreted reasonable results.Apparently, we can recognize the upward trend in figure 3.3

Table 3.3: The numbers of Crude materials, inedible, except fuels as predicted

\begin{tabular}{|c|c|c|c|c|c|}
\hline Values & Original (1) & Prediction (2) & $\begin{array}{c}\text { Error }[(2-1) / 1] \\
\%\end{array}$ & $\begin{array}{c}\text { Residual } \\
\text { Error }\end{array}$ & AGO \\
\hline 2007 & 3,450 & 3450 & $0.0000 \%$ & 0 & 3,450 \\
\hline 2008 & 3,624 & 3303 & $8.8678 \%$ & $(321)$ & 7,074 \\
\hline 2009 & 2,699 & 3441 & $27.4965 \%$ & 742 & 9,773 \\
\hline 2010 & 3,527 & 3585 & $1.6569 \%$ & 58 & 13,300 \\
\hline 2011 & 4,443 & 3736 & $15.9173 \%$ & (707) & 17,743 \\
\hline 2012 & 3,960 & 3892 & $1.7056 \%$ & (68) & 21,703 \\
\hline 2013 & 3,761 & 4056 & $7.8355 \%$ & 295 & 25,464 \\
\hline 2014 & $?$ & 4226 & $?$ & $?$ & $?$ \\
\hline 2015 & $?$ & 4403 & $?$ & $?$ & $?$ \\
\hline 2016 & $?$ & 4588 & $?$ & $?$ & $?$ \\
\hline 2017 & $?$ & 4780 & $?$ & $?$ & $?$ \\
\hline
\end{tabular}




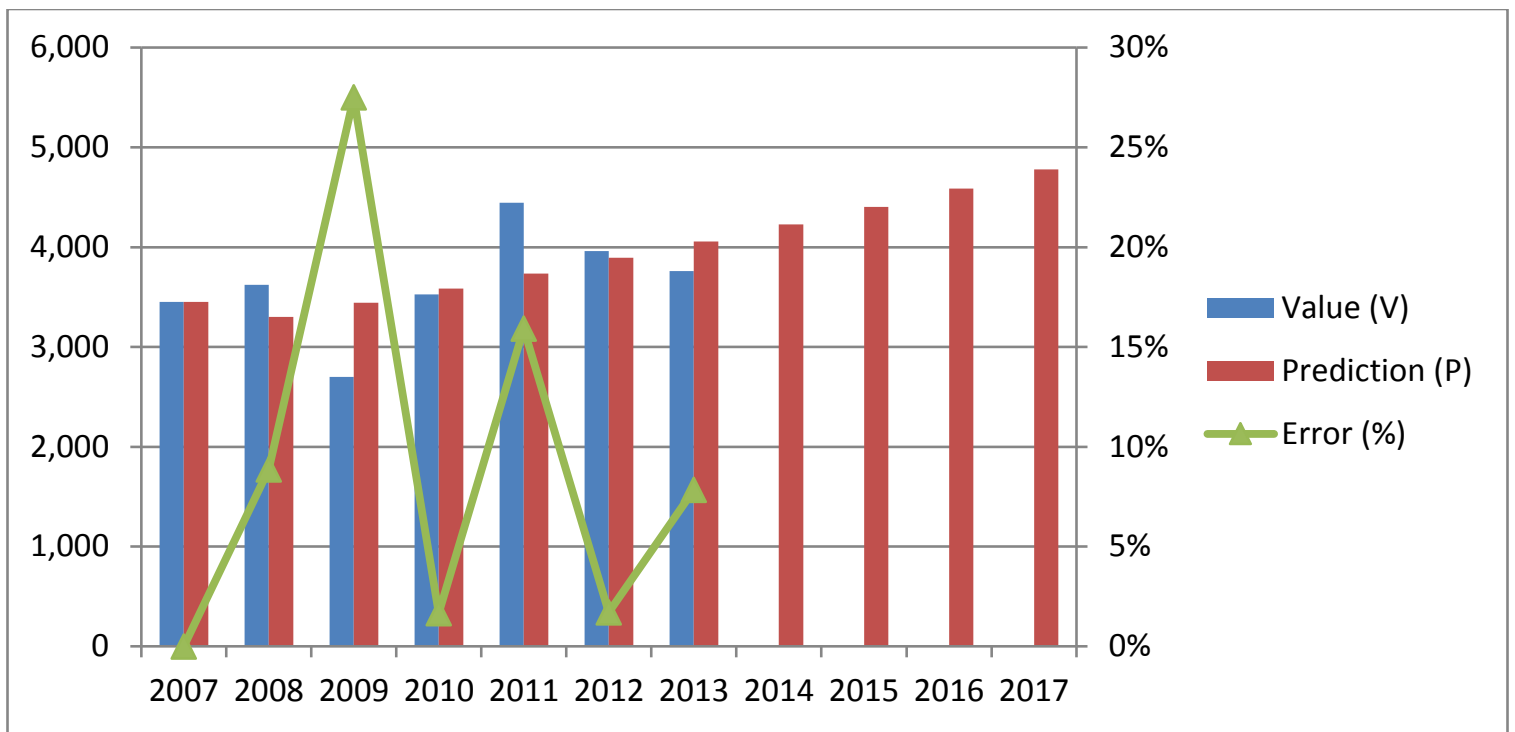

Figure 3.3: The sequence step of Crude materials, inedible, except fuels predicted

\section{Mineral fuels, lubricants and related materials}

Table 3.4 shows a significant increase in the export value of mineral fuels, lubricants and related materials in the past-present-future time. The export amounted to around \$US 24757 million in 2014, and the amount continues to rise over \$US 2000 million by each year. In 2017 the export amounted to around \$US 33464 million. Figure 3.4 also illustrates the upward trend. The forecasting errors are pretty good (below32.55\%), which indicate the method used in the paper is doing well.

Table 3.4: The numbers of Mineral fuels, lubricants and related materials as predicted

\begin{tabular}{|c|c|c|c|c|c|}
\hline Values & Original (1) & Prediction (2) & $\begin{array}{c}\text { Error }[(2-1) / 1] \\
\%\end{array}$ & $\begin{array}{c}\text { Residual } \\
\text { Error }\end{array}$ & AGO \\
\hline 2007 & 13,749 & 13749 & $0.0000 \%$ & 0 & 13,749 \\
\hline 2008 & 18,628 & 13549 & $27.2630 \%$ & (5079) & 32,377 \\
\hline 2009 & 11,302 & 14981 & $32.5544 \%$ & 3679 & 43,679 \\
\hline 2010 & 14,397 & 16564 & $15.0551 \%$ & 2167 & 58,076 \\
\hline 2011 & 17,436 & 18315 & $5.0411 \%$ & 879 & 75,512 \\
\hline 2012 & 21,608 & 20250 & $6.2827 \%$ & (1358) & 97,120 \\
\hline 2013 & 23,173 & 22390 & $3.3770 \%$ & (783) & 120,293 \\
\hline 2014 & $?$ & 24757 & ? & $?$ & $?$ \\
\hline 2015 & $?$ & 27373 & $?$ & $?$ & $?$ \\
\hline 2016 & $?$ & 30265 & $?$ & $?$ & $?$ \\
\hline 2017 & $?$ & 33464 & $?$ & ? & $?$ \\
\hline
\end{tabular}




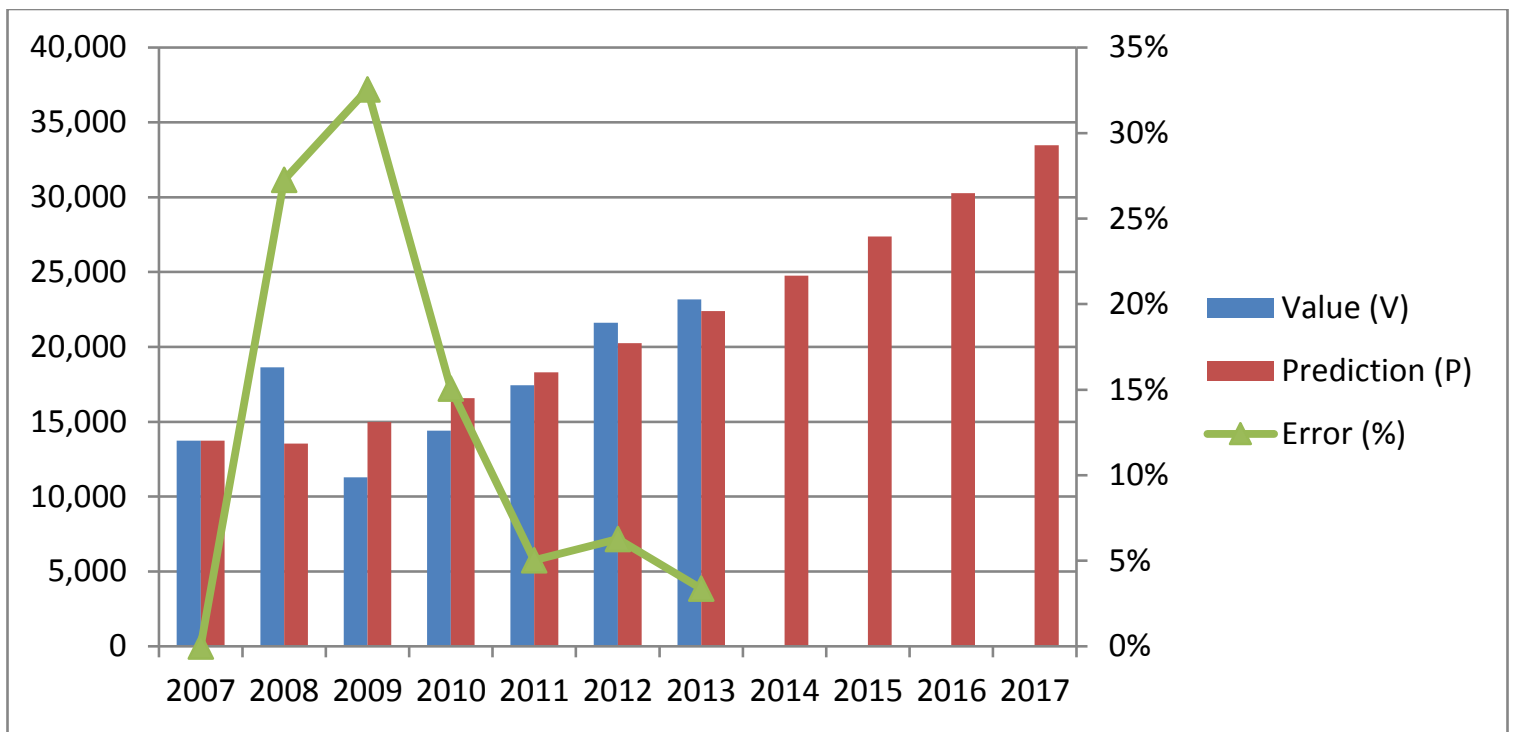

Figure 3.4: The sequence step of Mineral fuels, lubricants and related materials predicted Animal and vegetable oils, fats and waxes

In table 3.5, GM $(1,1)$ model gives us the predicted export value of thesemerchandiseslike animal and vegetable oils, fats and waxes in 2014, 2015, 2016, and 2017 and the future numbers for these future years will be \$US 117 million; \$US 127 million; \$US 138 million; and \$US 150 million respectively. Figure 3.5 shows this upward trend in the mount of export for the next four years. The residual errors of forecasting are ranging from only $0.00 \%$ to $15.89 \%$ show excellent forecasting ability.

Table 3.5: The numbers of Animal and vegetable oils, fats and waxes as predicted

\begin{tabular}{|c|c|c|c|c|c|}
\hline Values & Original (1) & Prediction (2) & $\begin{array}{c}\text { Error }[(2-1) / 1] \\
\%\end{array}$ & $\begin{array}{c}\text { Residual } \\
\text { Error }\end{array}$ & AGO \\
\hline 2007 & 62 & 62 & $0.0000 \%$ & 0 & 62 \\
\hline 2008 & 79 & 72 & $9.4872 \%$ & (7) & 141 \\
\hline 2009 & 67 & 78 & $15.8969 \%$ & 11 & 208 \\
\hline 2010 & 82 & 84 & $2.8353 \%$ & 2 & 290 \\
\hline 2011 & 100 & 92 & $8.4274 \%$ & (8) & 390 \\
\hline 2012 & 97 & 99 & $2.5187 \%$ & 2 & 487 \\
\hline 2013 & 108 & 108 & $0.0091 \%$ & (0) & 595 \\
\hline 2014 & $?$ & 117 & ? & $?$ & $?$ \\
\hline 2015 & $?$ & 127 & $?$ & $?$ & $?$ \\
\hline 2016 & $?$ & 138 & $?$ & $?$ & $?$ \\
\hline 2017 & ? & 150 & $?$ & ? & $?$ \\
\hline
\end{tabular}




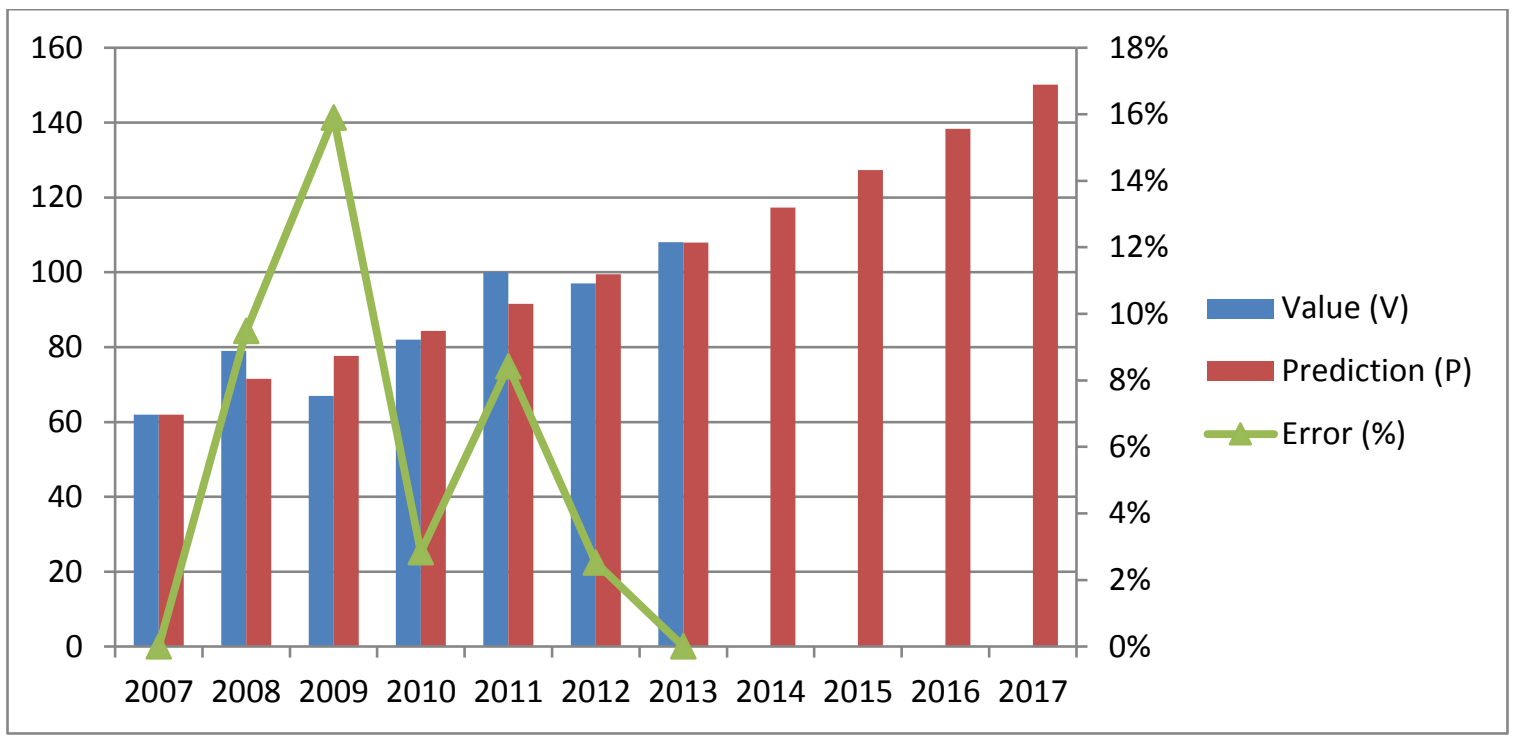

Figure 3.5: The sequence step of Animal and vegetable oils, fats and waxes predicted

\subsection{Balance of Trade}

The commercial balance is the difference between the monetary value of exports and imports of output in an economy over a certain period, measured in the currency of that economy. It is the relationship between a nation's imports and exports. A positive balance is known as a trade surplus if it consists of exporting more than is imported; a negative balance is referred to as a trade deficit or, informally, a trade gap.

Trademeans the purchase and sales of commodities. In international trade, purchase and sale are replaced by imports and exports. Balance of trade is simply the difference between the value of exports and value of imports. Thus, the balance of trade denotes the differences of imports and exports of a merchandise of a country during the course of year. It indicates the value of exports and imports of the country in question. If the value of its exports over a period exceeds its value of imports, it is called favourable balance of trade and, conversely, if the value of total imports exceeds the total value of exports over a period, it is unfavourable balance of trade. The favourable balance of trade indicates good economic condition of the country.Measuring the balance of trade can be problematic because of problems with recording and collecting data. Factors that can affect the balance of trade include:

- The cost of production (land, labor, capital, taxes, incentives, etc.)

- The cost and availability of raw materials, intermediate goods and other inputs; 
- Exchange rate movements;

- Multilateral, bilateral and unilateral taxes or restrictions on trade;

- Non-tariff barriers such as environmental, health or safety standards;

- $\quad$ The availability of adequate foreign exchange with which to pay for imports; and

- $\quad$ Prices of goods manufactured at home (influenced by the responsiveness of supply)

Foreign trade has been the engine of Taiwan's rapid growth during the past 40 years. Main trading partners are Mainland China \& Hong Kong, USA, Japan, Europe and ASEAN countries. Generally, export-oriented industrialization was particularly characteristic of the development of the national economies of Taiwan, as well as Hong Kong, South Korea, and the Asian Tigers [30]. Taiwan's main export products consisted of electronics (28\% of total), basic metals (9\%), plastics \& rubber $(8 \%)$, optical and photographic instruments (8\%) and chemicals (7\%). Main exports partners are Mainland China \& Hong Kong (42\% of total), USA (12\%), Japan (7\%), Europe (11\%) and ASEAN countries (15\%). A lack of natural resources had made Taiwan dependent on imports. Taiwan imports mostly mineral products and basic metals, electronic products, chemicals, machinery. Main import partners are Japan (21\% of total), Mainland China \& Hong Kong (14\%), USA (10\%), Europe (10\%) and ASEAN countries (11\%).

Collected data over a period of year from 2007 to 2013 in our study shown that towards the top 06 commodities likefood and live animals; beverages and tobacco; crude materials, inedible, except fuels; mineral fuels, lubricants and related materials; animal and vegetable oils, fats and waxes; as well as other commodities and transactions not classified elsewhere in the SITC, the value of total imports exceeded the total value of exports. Therefore, it reveals the situation of unfavourable balance of trade of these top commodities as listed above. Conversely, collected data also from that period of time (2013-2017) indicated that towards the rest of 04 top commodities like chemicals and related products; manufactured goods classified chiefly by material; machinery and transport equipment; and miscellaneous manufactured articles, the value of its exports over a period exceeds its value of imports, thus it is called favourable balance of trade for the situation of these merchandises.

For the future period of time, there will be a steady increase in both exports and imports value of all 10 items. Therefore, for the top 06 commodities likefood and live animals; beverages and tobacco; crude materials, inedible, except fuels; mineral fuels, lubricants and related materials; animal and vegetable oils, fats and waxes; and other commodities and transactions not 
classified elsewhere in the SITC, the value of total imports of these merchandise will continue to exceed the total value of exports. In many ways, some extend import would be beneficial for the economy, especially for countries in the developing stage. However, the trade deficit is too high will critically affect the economy.On the contrary, mentioned the rest of 04 top commodities like chemicals and related products; manufactured goods classified chiefly by material; machinery and transport equipment; and miscellaneous manufactured articles, the value of total exports over the period of year from 2014 to 2017 will continue toexceed its value of imports, thusfor these merchandises will experienced favourable balance of trade.

Taiwan, as standing as a developed country, usually imports a lot of raw materials from developing countries, e.g. ASEAN countries, etc. Typically, these imported materials are transformed into finished products, and might be exported after adding value.

After the further analysis of these indexes, we can find out some important information.

1. In this study, the author used the original data of the amount of import and export commodity during the years from 2007 to 2013, the author proposed a mathematical model of Grey forecasting to make a prediction of the total value of imports and exports of top commodities in Taiwan for the next 05 coming years from 2014to 2018.

2. With the usage of Grey forecastingmodels resulted in a very low mean absolute percentage error (MAPE),ranging from only $0.00 \%$ to $30 \%$ (see chapter 4), demonstrate its applicability in practice to provide accurate forecasts. Precise forecasting results obtained from this model are essential for the control and scheduling for the terminal operators in decision making and planning.

3. It is shown that there would be the stable trend to the predicted numbers on the total the value of import/exports of top 10 commodities in Taiwan during the recent and future years.

4. For the future period of time (2014-2018), there will be a steady increase in both exports and imports value of all 10 items.

The value of total imports of the below 06 types of merchandises will continue to exceed the total value of exports as they did in the past period (2007-2013). These merchandises will experienceunfavourable balance of trade. They are:

- $\quad$ food and live animals

- beverages and tobacco

- $\quad$ crude materials, inedible, except fuels 
- mineral fuels, lubricants and related materials

- $\quad$ animal and vegetable oils, fats and waxes

- $\quad$ and other commodities and transactions not classified elsewhere in the SITC

On the contrary, the rest of 04 top commodities show the value of total exportswill continue toexceed its value of imports. These merchandises will experience favourable balance of trade. They are:

- chemicals and related products

- manufactured goods classified chiefly by material

- machinery and transport equipment

- miscellaneous manufactured articles

\section{CONCLUSIONS}

This article applied Grey forecasting to construct a forecasting model. Precise forecasting results obtained from Grey System forecasting model is essential for the controlling, scheduling and making decision aboutwhichappropriate items for future import and export activities. Our approach helps to foreseen and determines which kinds of merchandise (items that on top and

prior import and export selection) will experience favourable balance of trade or unfavourable balance of trade.

The findings by Grey system theory, evaluated as a good and efficient model of forecasting with satisfactory results, may offer a valuable reference for government in drafting relevant policies for import and export activities and drawing up relevant policies for specified products.

The proposed forecasting model was supported by a rich and valid resource of data (collected from the official website of National Statistics - 2014 (Taiwan R.O.C)), compensating for the limitations of earlier studies. The results show that the residual error of the forecasting model is quite low, thus it can conclude that the model has high prediction validity and is clearly a viable means of forecasting the output value of an industry.

However, this study had one primary limitation that we only focused on the value of import/exports trade in Taiwan as a test case. In order to address this limitation, more research on data of other nations with different topic as well as with larger sample sizes, would be required.

To sum up, the effectiveness of Grey forecasting model verifies that the fitting degree of predicted value and actual value is very high. The combination Grey forecasting model with 
other forecasting model, like ARIMA model, SARIMA model, Neural Network, etc. may be more efficient and interesting. However, applying Grey forecasting model with the forecasting accuracy of the $\operatorname{GM}(1,1)$ to predict future value of import/exports trade in Taiwan can be used as an effective prediction method to provide a scientific reference for operators in decision making and planning.

\section{References}

[1] N. T. Nguyen and T. T. Tran, A two-stage study of grey system theory and DEA in strategic alliance: An application in Vietnamese fertilizing industry. Int. J. Adv. Appl. Sci. 5(9) (2018), 73-81.

[2] Lim, S. Y., \& Ho, C. M. Nonlinearity in ASEAN-5 export-led growth model: Empirical evidence from nonparametric approach. Econ. Model. 3(2) (2013), 136-145.

[3] Awokuse, T. O. Is the export-led growth hypothesis valid for Canada?.Can. J. Econ./Revue CanadienneD'économique, 36(1) (2003), 126-136.

[4] Awokuse, T. O. Exports, economic growth and causality in Korea. Appl. Econ. Lett. 12(11) (2005), 693-696.

[5] T. T. Tran, A strategic alliance study by performance evaluation and forecasting techniques: A case in the petroleum industry. Int. J. Adv. Appl. Sci. 5(2) (2018), 136-147.

[6] T. T. Tran, Evaluating and forecasting performance using past data of an industry: An analysis of electronic manufacturing services industry. Int. J. Adv. Appl. Sci. 3(12) (2016), 520.

[7] Mazumdar, J. Imported machinery and growth in LDCs. J. Develop. Econ. 65(1) (2001), 209224.

[8] Awokuse, T. O. Causality between exports, imports, and economic growth: Evidence from transition economies. Econ. Lett. 94(3) (2007), 389-395.

[9] Chou, C. C., Chu, C. W., \& Liang, G. S. A modified regression model for forecasting the volumes of Taiwan's import containers. Math. Computer Model. 47(9) (2008), 797-807.

[10] T. T. Tran, Evaluating and forecasting performance using past data of an industry: An analysis of electronic manufacturing services industry. Int. J. Adv. Appl. Sci. 3(12) (2016), 520. 
[11] X. Liu, A positive analysis on our import-export increase and economic growth. Modern Econ. Sci. 3 (2001), 007.

[12] Azgun, S., \&Sevinc, H. Are imports a reason of growth? Evidence from Turkey. Soc. Sci. 5(2) (2010), 66-69.

[13] Alam, M. M., Uddin, M. G. S., \&Taufique, K. M. R. Import inflows of bangladesh: the gravity model approach. Int. J. Econ. Finance, 1(1) (2014), p131.

[14] Zhang, W., \&amp; Zhao, S. Forecasting Research on the Total Volume of Import and Export Trade of Ningbo Port by Gray Forecasting Model. J. Software, 8(2) (2013), 466-471.

[15] Wong, H. T. Terms of trade and economic growth in Malaysia. Labuan Bull. Int. Bus. Finance, 2(2) (2004), 105-122.

[16] Djankov, S., \&Hoekman, B. Trade reorientation and post-reform productivity growth in Bulgarian enterprises. J. Policy Reform, 2(2) (1998), 151-168.

[17] Chuang, Y. C. Human capital, exports, and economic growth: a causality analysis for Taiwan, 1952-1995. Rev. Int. Econ. 8(4) (2000), 712-720.

[18] Ramos, F. F. R. Exports, imports, and economic growth in Portugal: evidence from causality and cointegration analysis. Econ. Model. 18(4) (2001), 613-623.

[19] Mah, J. S. Export expansion, economic growth and causality in China. Appl. Econ. Lett. 12(2) (2005), 105-107.

[20] Thangavelu, S. M., \&Rajaguru, G. Is there an export or import-led productivity growth in rapidly developing Asian countries? A multivariate VAR analysis. Appl. Econ. 36(10) (2004), 1083-1093.

[21] Joseph, K. J., \&Harilal, K. N. Structure and growth of India's it exports: Implications of an export-oriented growth strategy. Economic and Political Weekly, 36(34)(2001), 3263-3270.

[22] Milad, M. A., Ross, I. B. I., \&Marappan, S. Modeling and forecasting the volumes of Malaysia's import. Int. Conf. Glob. Trends Acad. Res. Bali, Indonesia Global Illuminators, Kuala Lumpur, Malaysia. (2014).

[23] T. T. Tran, Forecasting strategies and analyzing the numbers of incoming students: Case in Taiwanese vocational schools. Int. J. Adv. Appl. Sci. 4(9) (2017), 86-95.

[24] Fradinata E, Suthummanon S, and Sunthiamorntut W. Comparison of hybrid ANN models: A case study of instant noodle industry in Indonesia. Int. J. Adv. Appl. Sci. 4(8) (2017), 19-28, 
[25] N. T. Nguyen and T. T. Tran, Optimizing mathematical parameters of Grey system theory: an empirical forecasting case of Vietnamese tourism. Neural Comput. Appl. (2017), https://doi.org/10.1007/s00521-017-3058-9.

[26] N. T. Nguyen and T. T. Tran, Raising opportunities in strategic alliance by evaluating efficiency of logistics companies in Vietnam: a case of Cat Lai Port. Neural Comput. Appl. (2018b). https:// doi.org/10.1007/s00521-018-3639-2.

[27] Deng, J. L. Introduction to Grey System Theory. J. Grey Syst. 1(1) (1989), 1-24.

[28] Lin, Y., \& Liu, S. (2004a, October). A historical introduction to grey systems theory. In Systems, Man and Cybernetics, 2004 IEEE International Conference on, 3, 2403-2408.

[29] Nguyen, N. T., \& Tran, T. T. Facilitating an advanced product layout to prioritize hot lots in $450 \mathrm{~mm}$ wafer foundry in the semiconductor industry. Int. J. Adv. Appl. Sci. 3(6) (2016), 14-23.

[30] Ariff, M., \& Hill, H. Export-oriented industrialisation: The ASEAN experience (Vol. 49). Routledge, London/New York. (2010). 